\section{Seamless sterilisation}

From SciCan, STATIM B is a NEW 6-litre vacuum autoclave for enhanced infection control.

With smart features and enhanced digital capabilities, STATIM B enables smoother workflows and exceptional performance on a small footprint!

- Flexible loading options

- Shorter cycle times

- Maintenance reminders and video tutorials

- Programmable features; preheat the chamber before you open.

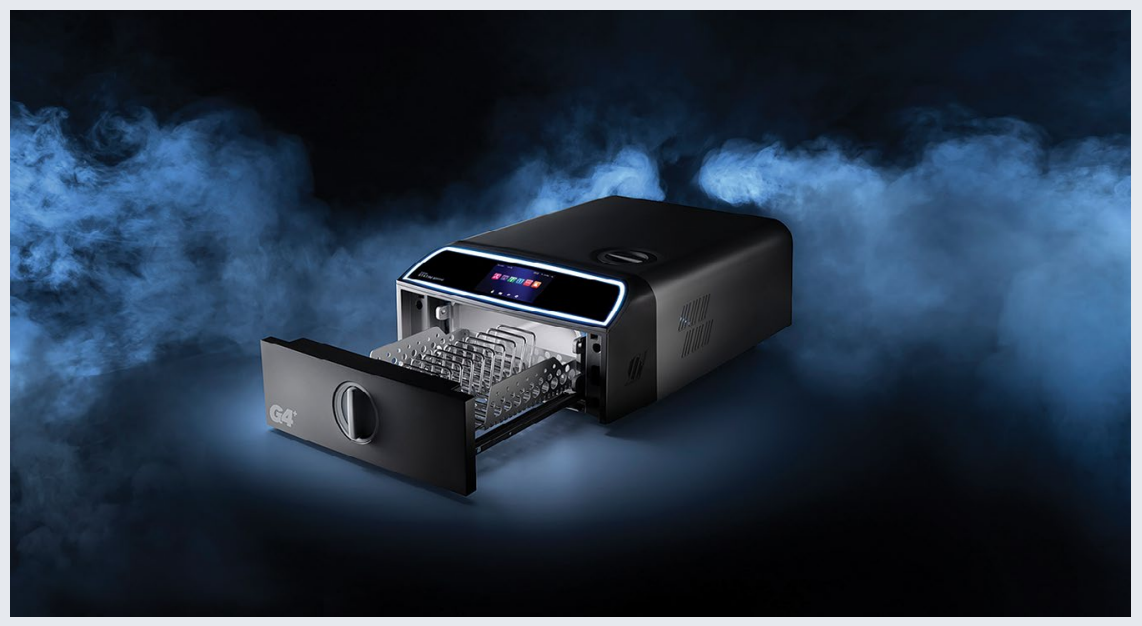

\section{Giving you the confidence to reach your goals in 2022}

Reaching your financial goals is much easier when you have expert assistance. The awardwinning team at money4dentists have decades of experience assisting dentists in reaching their goals and always go the extra mile to ensure that you receive the best guidance possible.

Whether you want to sell your practice, reassess your investments, look at your
Sterilised dry-wrapped loads can be delivered in 27 minutes with the STATIM B, and WiFi-enabled technology allows cycle logging, data storage and traceable load release. SciCan is part of COLTENE the developer and distributer of tools, equipment and materials for upgraded dentistry.

For details on the STATIM B, visit https://www.scican.com/eu/products/ autoclaves/statim-b/.

For more on COLTENE, visit www. coltene.com, email info.uk@coltene.com or call 08002545115 .

pension options or put plans in place for retirement, our team will use its industryspecific knowledge to ensure that you receive tailored, practical advice that will make all the difference.

For more information call 0845345 5060, email info@money4dentists.com or visit www.money4dentists.com.

\section{Take the next step in your career}

If you're looking to venture into implant dentistry, The One to One Implant Education could be the place for you.

Based in Harley Street, it offers training programmes designed by implant dentists for implant dentists. The courses, including a fully accredited postgraduate diploma, are designed to teach, mentor, and ignite a passion for evidence-based implant dentistry which will enable you to develop personally and professionally. There for you every step of the way, One to One Implant Education takes you through the entire process: from novice to implant dentist. It doesn't stop there; you will also receive ongoing support and mentoring throughout your career.

Make the decision for you today!

To reserve your place or to find out more, visit https://121implanteducation. co.uk or call 02074860000 .

\section{Give gums some TLC}

Looking after your patients' gums is an important step in the prevention of periodontal issues such as gingivitis, which can cause pain and discomfort for patients.

By recommending the Arm \& Hammer 100\% Natural Gum Protection toothpaste, patients can enjoy the benefits of its hero ingredient - baking soda! It helps promote a neutral $\mathrm{pH}$ due to its alkalinity and, combined with $1,450 \mathrm{ppm}$ of fluoride, can encourage the remineralisation of enamel.

This formula is clinically proven to improve gum health - as it reaches deep below the gumline - so patients can rest assured that their gums are receiving some well-needed TLC!

Consider recommending the Arm \& Hammer 100\% Natural Gum Protection toothpaste to patients, and help keep gums in tip-top shape.

For more information about the carefully formulated Arm \& Hammer toothpaste range, visit https://www. armandhammer.co.uk/ or email: ukenquiries@churchdwight.com.

Arm \& Hammer 100\% Natural Baking Soda Toothpaste range can now be purchased from Boots, Amazon and Superdrug, with further stockists following.

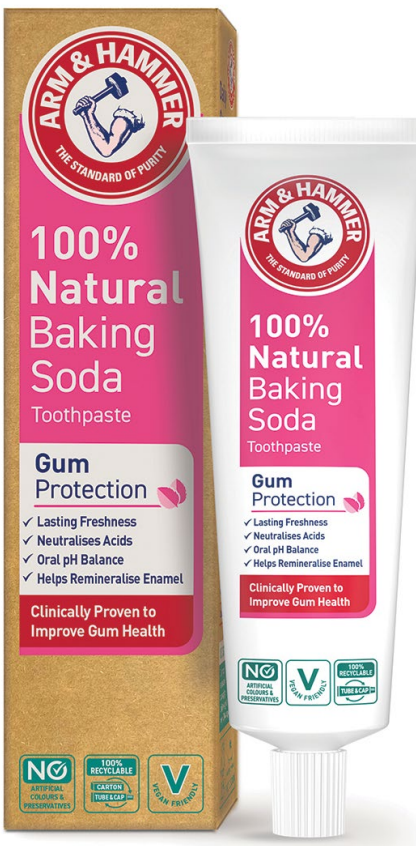

